Research Paper:

\title{
Nursing Students' Performance and Satisfaction Regarding the Classification of Pressure Injuries Using Simulation With Moulage
}

\author{
Derya Uzelli Yilmaz ${ }^{*}$ (D), Esra Akin ${ }^{1}$ (D), Duygu Yildirim ${ }^{1}$, Sinem Caliskan², Sevil Hamarat Tuncali²
}

1. Department of Fundamentals of Nursing, Faculty of Health Science, İzmir Kâtip Çelebi University, Izmir, Turkey.

2. Program of Fundamentals of Nursing, Institution of Health Science, Izmir Katip Celebi University, Izmir, Turkey.

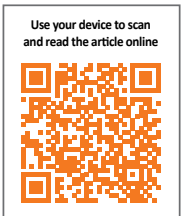

Citation: Uzelli Yilmaz, D., et al. 2021. Nursing Students' Performance and Satisfaction Regarding the Classification of Pressure Injuries Using Simulation With Moulage. Journal of Client-Centered Nursing Care, 7(4), pp. 311-318. https://doi. org/10.32598/JCCNC.7.4.395.1

https://doi.org/10.32598/JCCNC.7.4.395.1

Article info:

Received: 05 Jul 2021

Accepted: 28 Sep 2021

Published: 01 Nov 2021
Keywords:

Simulation, Moulage, Pressure injury, Assessment, Nursing

\section{A B S T RA C T}

Background: Simulation-based education is a widely utilized tool for experiential learning in nursing education. The aim of this study was to determine nursing students' performance and satisfaction in the classification of pressure injuries using simulation with moulage.

Methods: It is an evaluation study with a quasi-experimental, single-group, post-test design that was conducted in the spring semester of the 2019-2020 academic year in the Nursing Department of the Faculty of Health Sciences of Izmir Katip Celebi University, Izmir, Turkey. In total, 66 final-year nursing students, voluntarily participated in the Assessment of Pressure Injury using standardized patients. A student characteristics form, a Pressure Injury Classification Form, and a Moulage Satisfaction and Evaluation Form were used as data collection tools. Data were entered into SPSS 21, and the results of the analysis were described using descriptive statistics.

Results: It was found that $67.2 \%(n=45)$ of the students correctly assessed all the stages of pressure injury moulages on the standardized patients. Among the students, $62.1 \%(n=41)$ strongly agreed that their assessment skills of pressure injury improved after the simulation. The results related to students' satisfaction indicated that $77.3 \%(\mathrm{n}=51)$ of the students evaluated the moulages as realistic. The Mean \pm SD total score of students' evaluation of moulage simulation sessions on standard patients was $4.56 \pm 0.59$ (range $=1-5$ ).

Conclusion: This moulage is a simple, easily accessible, low-cost, and effective tool for teaching pressure injury assessment to nursing students. It can be used in clinical skills training and clinical assessment in nursing education.

\section{${ }^{*}$ Corresponding Author:}




\section{Highlights}

- Moulage may provide a unique opportunity to educate students on various clinical cases that would be difficult to achieve in clinical education.

- Most of the students correctly assessed all the stages of pressure injury moulages on the standardized patients.

- Most of the students strongly agreed that their assessment skills of pressure injury improved after the simulation.

- Most of the students evaluated the moulages as realistic.

\section{Plain Language Summary}

In nursing education, simulation use is becoming increasingly common as an additional training method for developing nursing skills. For simulated learning to be effective, it is important to create realistic visual and tactual experiences in the learning environment. This can be achieved by using the art of using makeup materials to create skin lesions called moulage. This study was done to determine nursing students' satisfaction and evaluation on the use of moulage to classify pressure injuries. In this study, most of the students correctly assessed all the stages of pressure injury moulages on the standardized patients and strongly agreed that their assessment skills of pressure injury improved after the simulation.

\section{Introduction}

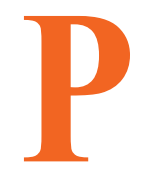

ressure Injury (PI) is a commonly occurring health issue throughout the world. It has a significant impact on the quality of life of the involved people and also imposes a major cost on healthcare settings (Tubaishat et al. 2018). PI in healthcare settings presents with large variations observed between different geographic zones and clinical settings (Tubaishat et al. 2018; Li et al. 2020). A systematic review conducted by Al Mutairi and Hendrie (2018) reported the global point prevalence of PIs in acute care hospitals as $14.8 \%$ and the period prevalence as $11.6 \%$, with a mean incidence of $6.3 \%$.

Nurses as vital members of the healthcare team play a significant role in the formation and classification of pressure injuries and also planning and implementation of nursing interventions to manage these skin lesions (Edsberg et al. 2016; Samuriwo \& Dowding 2014).

The National Pressure Injury Advisory Panel (NPIAP) has updated the stages of PI (stages 1- 4) with two additional stages called suspected deep tissue injury and unstageable pressure ulcers (Edsberg et al. 2016). When there is doubt about the depth of tissue damage and the stages are unstageable, it means that the PI stage is not clear. In these cases, the area of skin may look purple, dark, or red and a specialist needs to see the base of the injury. While in stage 1 , skin is intact with a localized area of erythema, which is red and does not blanch by pressure, in stage 2, it is characterized by partial-thickness skin loss with the exposed dermis, and skin appears viable, red or yellow, and moist. Stages 3 and 4 are characterized by full-thickness skin loss. However, in stage 3, unlike stage 4 , the fascia, muscle, tendon, ligaments, cartilage, or bone are not exposed (Edsberg et al. 2016; Hess 2020).

In practice, the differential diagnosis of these PIs is determined by clinical nurses based on visual assessment, which requires the competence, knowledge, and skills of a nursing assessor to identify these lesions (Edsberg et al. 2016). These competencies that enable nurses to identify and classify pressure injuries are learned during nursing education and are developed through encountering PIs during clinical practice (Tschannen et al. 2016; Ursavaş \& İşeri 2020; Yilmazer et al. 020; Sezgunsoy \& Basak 2020). Nursing students should be provided with the necessary facilities during the undergraduate program to learn these skills through practice using various instructional methods and modalities, such as simulation. In nursing education, simulation activities provide students with an opportunity to develop targeted skills proficiency, and also to enhance their critical thinking and diagnostic reasoning skills (Shin, Park, \& Kim 2015; Cant \& Cooper 2017). The effectiveness of a simulation in achieving learning outcomes is thought to be related to its fidelity, and moulage is increasingly described as a way to increase realism in simulation 
(Uzelli Yilmaz \& Sari 2018; Stokes-Parish, Duvivier \& Jolly 2019; Sarmasoglu et al. 2020). Several studies have been published on the evaluation of skin assessment skills among healthcare students (Seckman \& Ahearn 2010; Goulart et al. 2012; Hernandez et al. 2013; Wang et al. 2015; Flores \& Hess 2018; Zorn, Snyder \& Guthrie 2018; Uzelli Yilmaz \& Sari 2021). Sezgunsoy and Basak (2020) investigated whether using moulage on high-fidelity simulators improves nursing students' clinical skills to assess PI compared to using visuals. Their results revealed that simulation with moulage was effective in improving the skills of nursing students who received training for PI. Other studies also have shown that learners gain self-confidence and clinical skills through moulage when the simulation is used for skin and wound assessment (Hernandez et al. 2013; Scholtz, Sullivan \& Krishnamurthy 2016). Despite the frequent use of moulage in simulation, more research is needed to provide further evidence of the benefits related to the use of it in evaluating students' clinical assessment skills. This study was done to determine nursing students' performance and satisfaction in the classification of pressure injuries using simulation with moulage.

\section{Materials and Methods}

\section{Design, setting, and sample}

It was an evaluation study with a quasi-experimental, single-group, post-test design that was conducted between February and April 2019 in the Nursing Department of the Faculty of Health Sciences of Izmir Katip Celebi University, Izmir, Turkey. The study sample consisted of 66 final-year nursing students who volunteered for the assessment of the pressure injury course. The students were informed about the study process before the study. No incentive was offered to the subjects. They were also informed that they could leave the study at any time.

\section{Instruments}

Data were collected using a student characteristic form, a pressure injury classification form, and a moulage evaluation and satisfaction questionnaire.

Student characteristic form was used to collect data regarding the students' age and gender.

\section{Pressure injury classification form}

This form questioned how a student could classify PIs based on moulages designed for different areas of Standardized Patients (SPs) bodies. In this form, the stu- dent was asked to classify each wound based on the SP number; accordingly, in front of the number of each SP, he/she personally wrote the classification related to the wound. The number of correct responses of each student for each stage of PIs was then counted and recorded.

\section{Moulage evaluation and satisfaction questionnaire}

This researcher-made questionnaire consisted of five questions to determine the students' opinions about the authenticity and effectiveness of the moulages and their satisfaction with its use for the assessment of PIs. Four faculty members who were specialists in simulationbased learning evaluated the form in order to ensure its content validity before the interventions. The necessary adjustments related to the content of the questionnaire and the specific context of the study were made based on their recommendations. The Cronbach's alpha was calculated as 0.78 . The questions were scored on a five-point Likert scale by the students (1: strongly disagree to 5: strongly agree). The resulted scores ranged from 5 to 25 (with a mean of 1-5) and the higher scores indicated better evaluation or more satisfaction. The mean score of answers to each question was used to evaluate students 'opinions about the questions and the total mean score indicated students' general opinion about the use of moulage.

\section{Initial preparation}

\section{Moulage preparation}

The moulages were prepared by a researcher experienced in moulage and simulation to characterize each stage of PI. The researchers identified volunteer patients with different stages of pressure ulcers in various wards of the university hospital, and then, two ostomy wound care nurses were consulted about the PI stages. Identified PIs were photographed as the guiding reference for the appearance of the moulages. In order to choose the right materials, stage-specific skin appearances were determined. The material needed to produce the moulage representing the PI was selected, and after several experiments, safe materials (not harming the standardized patients' skin) were determined as suitable to simulate PI.

\section{Preparation of standardized patients}

The SPs who were willing to cooperate were selected to participate according to the University SPs program. A feedback guide was designed concerning the SPs' tasks, responsibilities, and scenarios, and their performance was standardized. Although sacral PI is one of the most common types of injury (Edsberg et al. 2016), the mou- 
lages were not applied to this area due to psychological safety issues for SPs. Different stages of pressure ulcer moulages were applied to different parts of standard patients' bodies (including right and left wrist, heel, and tibial region) so that each stage of wounds was present on two SPs to prevent prediction of wound classification.

\section{Study procedure}

\section{Theoretical lesson}

PI assessment was included in the curriculum of the fundamentals of the nursing internship course. In the implementation stage of the research, all the students participated in the PI assessment lecture. The lecture included two 2-hour interactive presentations by the researcher. The presentation consisted of the main components of risk assessment, staging, and evaluation of PI. After completing the presentation, 2 hours of practical training was completed using a case analysis technique in the classroom setting. Visuals of different stages of PI were also shown to discuss cases with students, and students answered questions posed by the researchers. The factors involved in the formation of pressure ulcers, such as patients' medical and injury history, incontinence, immobility, and nutritional status were also discussed.-

\section{Assessment of the students' performance}

One week after the theoretical lesson, the performance of all students in the classification of simulated pressure ulcers was evaluated. The simulation session was started with five minutes of pre-briefing. The PI assessment by students in the simulation session lasted 10 minutes. All the students performed the classification individually and the same researcher as a facilitator observed their performance from the simulation control room. Each student classified the stage of the injuries of all SPs (students did not contact each other until the end of the classification stage). When all the students finished the performance assessment, a debriefing session was performed. The debriefing session was conducted using the Promoting Excellence and Reflective Learning in Simulation (PEARL) method. The PEARLS method consists of four stages; "Reactions, Description, Analysis and Summary" (Eppich \& Cheng 2015). Accordingly, the facilitator asked questions to assess the students' ability for simulation debriefing.

Immediately after the simulation performance assessment, all the students completed the moulage evaluation and satisfaction questionnaire.

\section{Data analysis}

The data were analyzed by using SPSS/WIN 21. In the analysis of the descriptive data, numerical values, percentages, means, and standard deviations were used. The responses of the students on the pressure injury classification form were presented as numerical values and percentages.

\section{Results}

The Mean \pm SD age of the students was $22.12 \pm 0.81$ years and the majority of them were female $(75.8 \%$; $\mathrm{n}=50)$. Among the students, 98.5\% $(\mathrm{n}=65)$ assessed stage 1 correctly, $87.9 \%(n=58)$ of them assessed stage 2 correctly, $86.4 \%(n=57)$ assessed stage 3 correctly, and $83.3 \%(n=55)$ of the students assessed stage 4 correctly (Figure 1). It was found that $67.2 \%(n=45)$ of the students assessed all the stages of PIs correctly.

Regarding the evaluation of the use of moulage in the classification of PIs, there was the highest level of agreement on an item that showed a realistic interpretation of moulage. $(77.3 \%, \mathrm{n}=51)$. Most of the students $(\% 60.6, \mathrm{n}=40)$ strongly agreed that the pressure injury moulage simulation

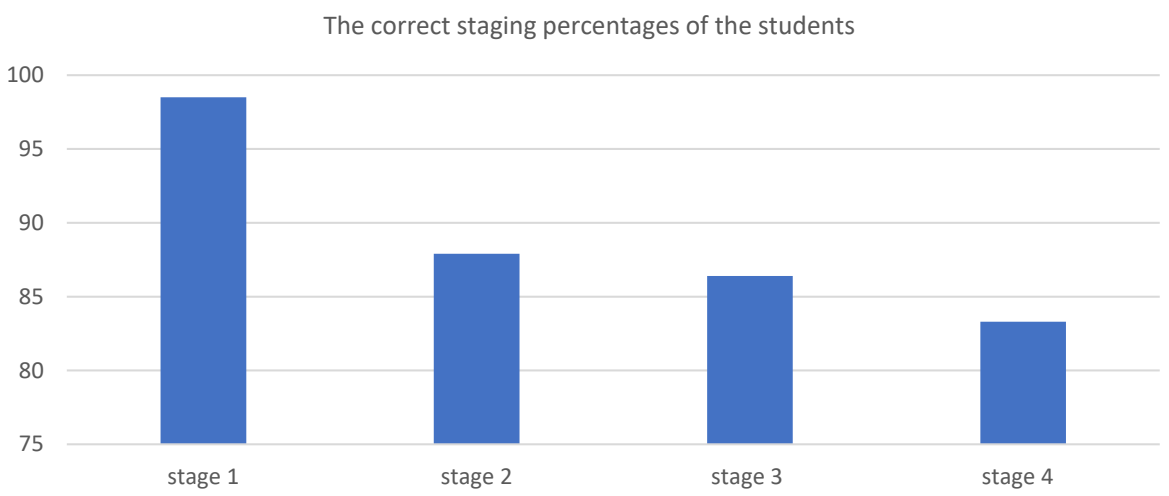

Figure 1. Percentage of the correct staging of simulated pressure ulcers by students $(n=66)$ 
Table 1. Students' evaluation of the pressure injury simulation by moulage and their satisfaction rate

\begin{tabular}{|c|c|c|c|c|}
\hline \multirow{2}{*}{ Items } & \multicolumn{3}{|c|}{ No. (\%) } & \multirow{2}{*}{ Mean \pm SD } \\
\hline & Slightly Agree* & Agree & Strongly Agree & \\
\hline $\begin{array}{l}\text { The pressure injury moulage simulation was close } \\
\text { to the real experience of assessing a real patient }\end{array}$ & $6(9.1)$ & $20(30.3)$ & $40(60.6)$ & $4.48 \pm 0.79$ \\
\hline $\begin{array}{l}\text { The appearance of pressure injury moulages was } \\
\text { realistic }\end{array}$ & $3(4.5)$ & $12(18.2)$ & $51(77.3)$ & $4.72 \pm 0.54$ \\
\hline $\begin{array}{c}\text { The moulages were realistic enough to be used in } \\
\text { nursing education }\end{array}$ & $0(0)$ & $18(27.2)$ & $48(72.8)$ & $4.68 \pm 0.63$ \\
\hline $\begin{array}{l}\text { The moulage helped me to better understand the } \\
\text { assessment of the pressure injury }\end{array}$ & $6(9.1)$ & $19(28.8)$ & $37(56.1)$ & $4.50 \pm 0.76$ \\
\hline $\begin{array}{l}\text { The moulages positively affected my skills in the } \\
\text { assessment of pressure injury }\end{array}$ & $8(11.1)$ & 21(31.8) & $41(62.1)$ & $4.40 \pm 0.80$ \\
\hline Total & & & & $4.56 \pm 0.59$ \\
\hline
\end{tabular}

Client- Centered Nursing Care

* Disagree and completely disagree columns were removed because students did not use these classification levels.

was close to the real experience of assessing patients in the clinical setting. Most of the students $(72.8 \%, n=48)$ also strongly agreed that the moulages were realistic enough to be used in nursing education. Also, $56.1 \%(n=37)$ of the students strongly agreed that the moulage simulation helped them to better understand the assessment of pressure injury, $62.1 \%(n=41)$ of them stated that it positively affected their skills in the assessment of pressure injury and $62.1 \%(n=41)$ of the students strongly agreed that the moulage simulation improved their assessment skills. The Mean \pm SD overall evaluation score of the students was $4.56 \pm 0.59$ (range $=1-5$ ) (Table 1).

\section{Discussion}

The aim of this study was to determine nursing students' performance and satisfaction regarding the classification of pressure injuries using simulation with moulage. According to the results, the students achieved a correct classification rate, which showed that moulage simulation evoked and presented a real clinical situation and their information on classifying of PI was cognizant. Smith-Stoner (2011) used moulages and found that in addition to correct classification, the students remembered the content in other weeks. Yilmazer et al. (2020) also revealed that SP interactions are an efficient learning modality for nursing students' preventive interventions on pressure ulcers.

In nursing clinical education, because of the short duration of the internship period, students are less likely to encounter patients with PI and are unable to develop their skills in identifying and classifying PIs. It seemed that the moulages used in our study activated the students' visual sense and allowed the students to identify and classify pressure injuries. In a study by Flores and Hess (2018), using SPs dressed in moulage did not improve pharmacy students' visual ability to assess skin disorders compared to using picture-based paper cases. However, students preferred SPs dressed in moulage only when learning the assessment of skin disorders. According to the current study's findings, it can be seen that the satisfaction levels of the students towards using moulage were high. Considering the potential problems in the evaluation of students in a clinical setting, students' opinions are of considerable importance in terms of the usability of moulage in student assessment. The students' evaluation suggested that the PI moulage looked realistic and was good enough to be used in their education. Moulage could provide an opportunity to discuss the clinical reasoning for the students who have difficulty in developing some clinical assessment skills during clinical practice due to the high number of students and patient safety issues.

In the current study, the responses to the question related to the understanding of the assessment of PIs using the moulage though positive, were not as strong as those rated for other questions. However, the percentage of correct staging was high among the students. These findings may suggest that the SPs simulation using moulages was successful in the evaluation of students' assessment skills. It has been shown that training for improving clinical assessment skills using moulage increased students' clinical skills and knowledge acquisition (Uzelli Yilmaz \& Sari 2021; Sezgunsoy \& Basak 2020; Seckman \& Ahearn 2010). A recent study by Uzelli Yilmaz and Sari (2021) found that the SP simulation with moulage is an effective method in increasing nursing students' skills to assess intravenous therapy complications. 
Other studies have also indicated that the inclusion of moulage in simulations is an effective way to develop students' self-confidence and self-efficiency levels (Hernandez et al. 2013; Scholtz, Sullivan \& Krishnamurthy 2016; Seckman \& Ahearn 2010).

\section{Conclusion}

The aim of this study was to determine nursing students' performance and satisfaction regarding the classification of pressure injuries using simulation with moulage. Our findings demonstrated that simulation with moulage on SPs is a usable strategy for PI assessment skills among nursing students and students reported high satisfaction with the moulage application. Simulation with moulage may provide a unique opportunity to educate students on various clinical cases that would be difficult to achieve in clinical education. To continue to advance our knowledge of the benefits and limitations of moulage, it will be necessary to examine whether the benefits translate into real clinical practice as well as the costs associated with implementing the varying strategies. Also, we recommend that future studies compare using SPs dressed in moulage with other methods of education to assess student nurses' PI classification skills and their satisfaction.

The main limitation of this study is its single-group posttest nature. Therefore, the findings should be used with caution.

\section{Ethical Considerations}

\section{Compliance with ethical guidelines}

The necessary written permission for the research was obtained from the Ethical Committee of the Izmir Katip Celebi University (Reference number: 105/20.02.2019). Written consent was obtained from all participating students and SPs before the study.

\section{Funding}

This research did not receive any grant from funding agencies in the public, commercial, or non-profit sectors.

\section{Authors' contributions}

Study conception and design: Derya Uzelli Yilmaz, Esra Akin; Data collection: Derya Uzelli Yilmaz, Duygu Yildirim, Sinem Caliskan, Sevil Hamarat Tuncali; Data analysis and interpretation: Derya Uzelli Yilmaz, Duygu Yildirim, Sinem Caliskan; Drafting of the article: Derya Uzelli Yilmaz, Duygu Yildirim; Critical revision of the article: Esra Akin

\section{Conflict of interest}

The authors declared no conflict of interest.

\section{Acknowledgments}

The authors would like to appreciate the Izmir Katip Celebi University, and also the students and standardized patients who participated in the study.

\section{References}

Al Mutairi, K. B. \& Hendrie, D., 2018. Global incidence and prevalence of pressure injuries in public hospitals: A systematic review. Wound Medicine, 22, pp. 23-31. [DOI:10.1016/j. wndm.2018.05.004]

Cant, R. P. \& Cooper, S. J., 2017. Use of simulation-based learning in undergraduate nurse education: An umbrella systematic review. Nurse Education Today, 49, pp. 63-71. [DOI:10.1016/j. nedt.2016.11.015] [PMID]

Edsberg, L. E., et al. 2016. Revised national pressure ulcer advisory panel pressure injury staging system: Revised pressure injury staging system. Journal of Wound Ostomy \& Continence Nursing, 43(6), pp. 585-97. [DOI:10.1097/ WON.0000000000000281] [PMID] [PMCID]

Eppich, W. \& Cheng, A., 2015. Promoting Excellence and Reflective Learning in Simulation (PEARLS): Development and rationale for a blended approach to health care simulation debriefing. Simulation in Healthcare, 10(2), pp. 106-15. [DOI:10.1097/SIH.0000000000000072] [PMID]

Flores, E. K. \& Hess, R., 2018. Comparing teaching methods on skin disorders using standardized patients dressed in moulage vs paper cases. American Journal of Pharmaceutical Education, 82(7), pp. 773-8. [DOI:10.5688/ajpe6636] [PMID] [PMCID]

Hernandez, C., et al. 2013. Assessing students' ability to detect melanomas using standardized patients and moulage. Journal of American Academy Dermatology, 68(3), pp. 83-8. [DOI:10.1016/j.jaad.2011.10.032] [PMID]

Hess, C. T., 2020. Classification of pressure injuries. Advances in Skin \& Wound Care, 33(10), pp. 558-9. [DOI:10.1097/01. ASW.0000697324.90597.6d] [PMID]

Goulart, J. M., et al. 2012. Recognition of melanoma: A dermatologic clinical competency in medical student education Journal of American Academy Dermatology, 67(4), pp. 606-11. [DOI:10.1016/j.jaad.2011.12.007] [PMID]

Li, Z., et al. 2020. Global prevalence and incidence of pressure injuries in hospitalised adult patients: A systematic review and meta-analysis. International Journal of Nursing Studies, 105, p. 103546. [DOI:10.1016/j.ijnurstu.2020.103546] [PMID]

Samuriwo, R. \& Dowding, D., 2014. Nurses' pressure ulcer related judgements and decisions in clinical practice: A systematic review. International Journal of Nursing Studies, 51(12), pp. 1667-85. [DOI:10.1016/j.ijnurstu.2014.04.009] [PMID] 
Sarmasoglu, S., et al. 2020. Pediatric severe burn moulage: Recipe and evaluation from the burn team. Clinical Simulation in Nursing, 49, pp, 32-9. [DOI:10.1016/j.ecns.2020.05.003]

Seckman, A. C. \& Ahearn, T., 2010. Utilizing simulation and moulage techniques: Performing thorough skin assessments in a baccalaureate nursing program. Clinical Simulation in Nursing, 6(3), p. e122. [DOI:10.1016/j.ecns.2010.03.058]

Sezgunsay, E. \& Basak, T., 2020. Is Moulage effective in improving clinical skills of nursing students for the assessment of pressure injury? Nurse Education Today, 94, p. 104572. [DOI:10.1016/j. nedt.2020.104572] [PMID]

Scholtz, J., Sullivan, M. \& Krishnamurthy, S., 2016. Are standardized patient exams with melanoma moulages a more accurate reflection of medical student concept mastery than standard multiple-choice exams? Journal of American Academy Dermatology, 74(5), pp. 110-7. [DOI:10.1016/j.jaad.2016.02.432]

Shin, S., Park, J. H. \& Kim, J. H., 2015. Effectiveness of patient simulation in nursing education: Meta-analysis. Nurse Education Today, 35(1), pp. 176-82. [DOI:10.1016/j.nedt.2014.09.009] [PMID]

Smith-Stoner, M., 2011. Using moulage to enhance educational instruction. Nurse Educator, 36(1), pp. 21-4. [DOI:10.1097/ NNE.0b013e3182001e98] [PMID]

Stokes-Parish, J., Duvivier, R. \& Jolly, B., 2019. Expert opinions on the authenticity of moulage in simulation: A Delphi study. Advances in Simulation, 4, p. 16. [DOI:10.1186/s41077-019-0103-z] [PMID] [PMCID]

Tschannen, D., Mckay, M. \& Steven, M., 2016. Improving pressure ulcer staging accuracy through a nursing student experiential intervention. Journal of Nurse Education, 55(5), pp. 266-70. [DOI:10.3928/01484834-20160414-05] [PMID]

Tubaishat, A., et al. 2018. Pressure ulcers prevalence in the acute care setting: A systematic review, 2000-2015. Clinical Nursing Research, 27(6), pp. 643-59. [DOI:10.1177/105477381770554] [PMID]

Ursavaş, F. E. \& İşeri, Ö., 2020. Effects of education about prevention of pressure ulcer on knowledge and attitudes of nursing students. Journal of Tissue Viability, 29(4), pp. 331-6. [DOI:10.1016/j. jtv.2020.06.006] [PMID]

Uzelli Yılmaz, D. \& Sar1, D., 2021. Examining the effect of simulation-based learning on intravenous therapy administration' knowledge, performance, and clinical assessment skills of firstyear nursing students. Nurse Education Today, 102, p. 104924. [DOI:10.1016/j.nedt.2021.104924] [PMID]

Uzelli Yılmaz, D. \& Sarı, D., 2018. The use of moulage for providing "fidelity" in nursing education. Journal of Florence Nightingale, 26(2), pp. 141-8. [DOI:10.26650/fnjn.42714]

Yilmazer, T., et al. 2020. The impact of standardized patient interactions on nursing students' preventive interventions for pressure ulcers. Journal of Tissue Viability, 29(1), pp. 19-23. [DOI:10.1016/j. jtv.2019.11.004] [PMID]

Wang, S., et al. 2015. Medical student melanoma detection rates in white and African American skin using moulage and standardized patients. Clinical Research in Dermatolgy, 2(1), pp. 1-4 [DOI:10.15226/2378-1726/2/1/00109]

Zorn, J., Snyder, J. \& Guthrie, J., 2018. Use of moulage to evaluate student assessment of skin in an objective structured clinical examination. Journal of Physician Assistant Education, 29(2), pp. 99103. [DOI:10.1097/JPA.0000000000000205] [PMID] 
This Page Intentionally Left Blank 